\title{
ON THE SUM OF SQUARED LOGARITHMS INEQUALITY AND RELATED INEQUALITIES
}

\section{Fozi M. DANnAN, PATRIZIO NeFF AND Christian ThiEL}

Abstract. We consider the sum of squared logarithms inequality and investigate possible connections with the theory of majorization. We also discuss alternative sufficient conditions on two sets of vectors $a, b \in \mathbb{R}_{+}^{n}$ so that

$$
\sum_{i=1}^{n}\left(\log a_{i}\right)^{2} \leqslant \sum_{i=1}^{n}\left(\log b_{i}\right)^{2}
$$

Generalizations of some inequalities from information theory are obtained, including a generalized information inequality and a generalized $\log$ sum inequality, which states for $a, b \in \mathbb{R}_{+}^{n}$ and $k_{1}, \ldots, k_{n} \in[0, \infty)$ :

$$
\sum_{i=1}^{n} a_{i} \log \prod_{s=1}^{m}\left(\frac{a_{i}}{b_{i}}+k_{s}\right) \geqslant \log \prod_{s=1}^{m}\left(1+k_{s}\right) .
$$

Mathematics subject classification (2010): 26D05, 26 D07.

Keywords and phrases: Sum of squared logarithms inequality, exponential functions inequalities, log sum inequality, Gibbs' inequality, information inequality.

\section{REFERENCES}

[1] M. BÎRSAN, P. NEFF, AND J. LANKEIT, Sum of squared logarithms-an inequality relating positive definite matrices and their matrix logarithm, J. Inequal. Appl. 2013.

[2] G. Cardano, Ars Magna, Petreius, 1545.

[3] T. Cover And J. Thomas, Elements of information theory, Wiley, 2012.

[4] G. H. Hardy, J. E. Littlewood, and G. Pólya, Inequalities, Cambridge University Press, 1952.

[5] A. Marshall, I. Olkin, And B. ARnold, Inequalities: Theory of majorization and its applications: Theory of majorization and its applications, Springer Series in Statistics, Springer, 2010.

[6] D. S. Mitrinović, J. E. PeČArić, AND A. M. FInK, Classical and new inequalities in analysis, Springer, 1993.

[7] P. NefF, B. Eidel, F. Osterbrink, And R. Martin, A Riemannian approach to strain measures in nonlinear elasticity, Comptes Rendus Mécanique, 342, 4 (2014), 254-257.

[8] P. NefF, I. D. GhiBA, And J. LAnkeit, The exponentiated Hencky-logarithmic strain energy. Part I: Constitutive issues and rank-one convexity, J. Elasticity (2014), 1-92.

[9] P. NefF, J. Lankeit, I.-D. Ghiba, R. Martin, And D. Steigmann, The exponentiated Henckylogarithmic strain energy. Part II: Coercivity, planar polyconvexity and existence of minimizers, $\mathrm{Z}$. Angew. Math. Phys. (2015), 1-23.

[10] P. NefF, J. LANKeIt, AND A. MAdEO, On Grioli's minimum property and its relation to Cauchy's polar decomposition, Internat. J. Engrg. Sci. 80 (2014), 209-217.

[11] P. NefF, Y. Nakatsukas A, AND A. FISCHLE, A logarithmic minimization property of the unitary polar factor in the spectral norm and the Frobenius matrix norm, SIAM J. Matrix Anal. Appl. 35, 3 (2014), 1132-1154.

[12] W. Pompe And P. NEFF, On the generalized sum of squared logarithms inequality, J. Inequal. Appl. 2015 (1), 1-17. 
[13] M. Томіс, Théoreme de Gauss relatif au centre de gravité et son application, Bull. Soc. Math. Phys. Serbie 1 (1949), 31-40.

[14] H. WEYL, Inequalities between the two kinds of eigenvalues of a linear transformation, Proc. Natl. Acad. Sci. USA 35, 7 (1949), 408. 